\title{
USING THE CLIMATIC MENU IN R-INSTAT
}

\author{
$\underline{\text { James Musyoka }}^{1,2}$, Steven Kogo ${ }^{1}$, Danny Parsons ${ }^{3}$, Lily Clements ${ }^{4}$, Shadrack Kibet ${ }^{1}$, David Stern ${ }^{5}$, \\ and Roger Stern ${ }^{4,5}$ \\ ${ }^{1}$ African Maths Initiative \\ ${ }^{2}$ Maseno University \\ ${ }^{3}$ Supporting African Maths Initiatives \\ ${ }^{4}$ Statistics for Sustainable Development \\ ${ }^{5}$ University of Reading \\ jkmusyoka@maseno.ac.ke
}

Every African country has a National Meteorological Service (NMS) which provides shortterm forecasts, provides seasonal forecasts, and holds historical climactic data. Historical data are used in many applications, including PICSA (Participatory Integrated Climatic Services for Agriculture). The PICSA project uses historical climatic data to support farmers and intermediaries. Analyses of historical data currently use a statistics package called Instat; this is soon to be replaced by the facilities in the new climatic menu of R-Instat. This poster focusses on the climatic menu of R-Instat, which includes daily climatic data on rainfall, temperatures, and sunshine hours, plus satellite data since 1983.

Statistics education across Africa is still usually taught theoretically. Climatic data provides a rich set of opportunities to enhance learning in ways that are interesting to students. The poster mentions some ways to process this data using the climatic menu in R-Instat. We consider "events" such as the start, end and length of the rainy season, together with spell lengths and extreme rainfalls during the season. We also consider wind speed and direction, which can be presented as circular graphs and be related to wind energy. 